\title{
Frequência do carcinoma basocelular na população menor de 50 anos: estudo do serviço e revisão de literatura
}

\author{
Frequency of basal cell carcinoma in a population younger than 50 years of \\ age: clinical study and literature review
}

\author{
Ana Carolina Conde Almeida ${ }^{1}$ \\ Bruno Conte ${ }^{3}$ \\ Rilde Plutarco Veríssimo ${ }^{5}$
}

\author{
Thamy Yamashita ${ }^{2}$ \\ Amílcar Castro Mattos ${ }^{4}$ \\ Maria Cristina Furian Ferreira ${ }^{6}$
}

\begin{abstract}
Resumo: O carcinoma basocelular é a neoplasia maligna cutânea mais comum em humanos, que pode ser prevenida e diagnosticada precocemente. O propósito deste estudo é apresentar os achados clínicos e microscópicos do carcinoma basocelular na população menor de 50 anos. Realizaram-se exames microscópicos em múltiplos cortes de lesão de pele e fez-se revisão da literatura pertinente.

Palavras-chave: Adulto jovem; Carcinoma basocelular; Dermatite fototóxica

Abstract: Basal cell carcinoma is the most common type of malignant cutaneous neoplasm in humans, and it can be prevented and diagnosed early. The purpose of this study is to present clinical and microscopic findings of basal cell carcinoma in a population younger than 50 years of age. Microscopic examinations of multiple sections of skin lesion have been done, as well as a review of relevant literature.

Keywords: Young adult; Basal cell carcinoma; Phototoxic dermatitis
\end{abstract}

O carcinoma basocelular (CBC) é uma neoplasia cutânea que se origina de células basais epiteliais imaturas pluripotentes, que perderam sua capacidade de diferenciação e queratinização normais ${ }^{1-4}$ e dos anexos cutâneos.

A cabeça e o pescoço são os locais de predileção do tumor basocelular. Este tem sido descrito como o tumor maligno mais frequente em humanos, sendo comum a sua ocorrência em pacientes mais idosos. ${ }^{1,2,3}$ No entanto, tem-se observado que análises de grandes séries publicadas demonstram uma considerável variação nas taxas de incidência desse tumor. ${ }^{5-9}$

Estudou-se uma série de casos de pacientes com CBC do hospital universitário cuja idade era menor que 50 anos e compararam-se esses dados com outros da literatura médica. Os pacientes estudados foram, ${ }^{57} \mathrm{com}$ idade inferior a 50 anos, durante $\mathrm{O}$ período de 2000 a 2005 , cujas biópsias foram encaminhadas do serviço de patologia do hospital universitário, dos serviços de cirurgia plástica e dermatologia desse hospital ou ainda do hospital municipal.

De 2000 a 2005, em 62.565 biópsias, observaram-se 1.001 pacientes $(1,59 \%)$ com carcinoma basocelular. Cinquenta e sete pacientes com idades entre 15 e 49 anos apresentaram, em geral, lesões com aspecto papuloso, com bordas perláceas e irregulares. Cerca de 20 lesões $(35,08 \%)$ eram ulceradas. Nenhum deles apresentou quadro cutâneo de xeroderma pigmentoso ou outros indícios que poderiam estar associados a quadros sindrômicos. Desses 57 pacientes,

\footnotetext{
Recebido em 18.6.2006.

Aprovado pelo Conselho Consultivo e aceito para publicação em 6.10.09.

* Trabalho realizado no Serviço de Anatomia Patológica, Hospital e Maternidade Celso Pierro, Pontifícia Universidade Católica (PUC) de Campinas - Campinas (SP), Brasil. Conflito de interesse: Nenhum / Conflict of interest: None

Suporte financeiro: Nenhum / Financial funding: None

Médica formada pela Faculdade de Medicina, Centro de Ciências da Vida, Pontifícia Universidade Católica (PUC) de Campinas - Campinas (SP), Brasil Médica formada pela Faculdade de Medicina, Centro de Ciências da Vida, Pontifícia Universidade Católica (PUC) de Campinas - Campinas (SP), Brasil. Médico formado pela Faculdade de Medicina, Centro de Ciências da Vida, Pontifícia Universidade Católica (PUC) de Campinas - Campinas (SP), Brasil. Patologista, Serviço de Anatomia Patológica, Hospital e Maternidade Celso Pierro, Pontifícia Universidade Católica (PUC) de Campinas - Campinas (SP), Brasil. Patologista, Serviço de Anatomia Patológica, Hospital e Maternidade Celso Pierro, Pontifícia Universidade Católica (PUC) de Campinas - Campinas (SP), Brasil. Patologista, Serviço de Anatomia Patológica, Hospital e Maternidade Celso Pierro, Pontifícia Universidade Católica (PUC) de Campinas. Professora de Anatomia Patológica da Faculdade de Medicina, Centro de Ciências da Vida, Pontifícia Universidade Católica (PUC) de Campinas - Campinas (SP), Brasil. 


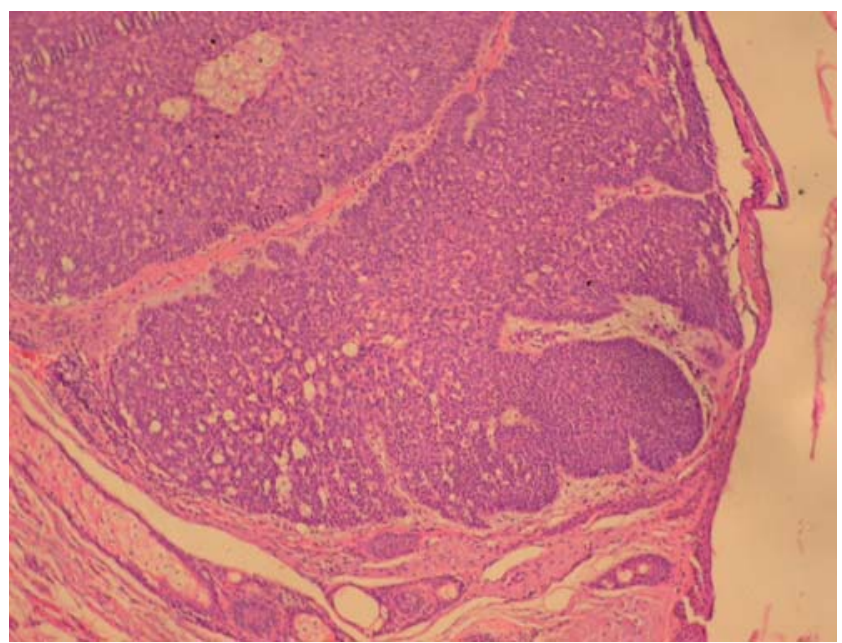

FiguRA 1: Histológico com brotos neoplásicos em padrão sólido

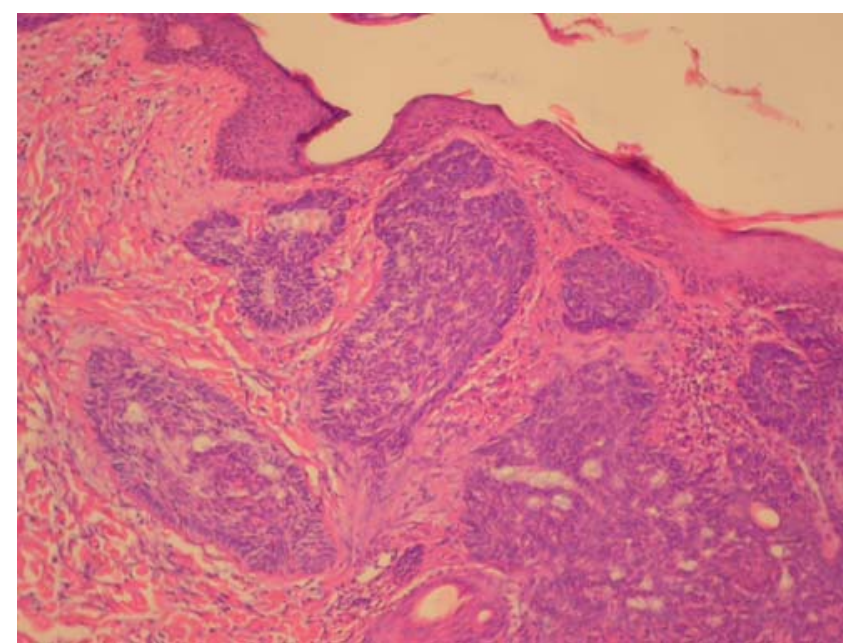

Figura 2: Lesão com padrão combinado exibindo diminutos brotos celulares sólidos e células neoplásicas isoladas em meio a tecido conjuntivo
11 (19,29\%) apresentavam exposição crônica ao sol por motivos ocupacionais. Um paciente apresentava lesões multifocais e 56 lesões únicas, isoladas.

A topografia mais encontrada foi face e pescoço (27 pacientes - 47,36\%), sendo que nariz e região temporal foram as mais frequentes, com cinco pacientes cada uma. Seis pacientes eram tabagistas. Dezesseis eram do sexo masculino e 15 , do sexo feminino. Um paciente era albino (o único com lesões multifocais).

Houve predomínio da forma sólida clássica (Figura 1) em 24 casos $(42,10 \%)$, quatro casos (16,66\%) apresentaram o padrão micronodular e cinco $(20,83 \%)$, o esclerodermiforme (subtipos combinados) (Figura 2). A forma sólida mostrava lesões com aspecto microscópico imaturo, de células escuras, basalóides, com aumento do número de mitoses e paliçada celular. A forma esclerodermiforme continha estroma denso e fibrosante, com perda da paliçada neoplásica periférica, enquanto a adenóide apresentava agrupamentos celulares de aspecto cribriforme, em geral, mantendo a paliçada celular periférica. A forma superficial apresentava-se com paliçada periférica na derme superior. A forma combinada com diferenciação escamosa apresentava células de grande citoplasma abundante eosinofílico semelhante às células do carcinoma epidermoide clássico.

Há consenso quanto ao progressivo aumento da incidência do CBC (em idosos e também em pacientes jovens não sindrômicos), com acentuada agressividade local, podendo cursar com deformidades ou ainda com metástases. Diversos autores concordam que latitude, exposição solar com pele desprotegida, depleção da camada de ozônio, herança étnica e tipo de pele (fotótipos I e II, por exemplo) são, provavelmente, os fatores que mais contribuem para essa grande variação. ${ }^{5-9}$

Um crescimento na incidência deste câncer na população mais jovem pode significar um crescimento exponencial na sua ocorrência na futura população idosa, pois quem teve $\mathrm{CBC}$ ou carcinoma epidermóide (CEC) tem maior propensão à recorrência desses tumores ao longo da vida, caso não mudem drasticamente os hábitos, especialmente, os relacionados aos fatores ambientais. ${ }^{8}$

Para que se entendam as taxas de incidência, características histológicas e história natural, alguns fenômenos dos CBCs têm sido mais bem observados também na população mais jovem. . $^{4,6,8}$ A exposição traumática ao sol, o tabagismo, o bronzeamento artificial, associados a alguns fatores genéticos - por exemplo, xeroderma pigmentoso, síndrome do nevo basocelular (Gorlin-Goltz) -, podem facilitar o aparecimento desses tumores nessa população. ${ }^{6-9}$ Considerando-se que fenômenos da histogênese tumoral ainda são pouco conhecidos,,$^{4,10}$ o comportamento preventivo parece ser a solução mais eficaz. 


\section{REFERÊNCIAS}

1. Stanley J, Miller MD. Biology of basal cell carcinoma (part I). J Am Acad Dermatol. 1991;24:1-13.

2. Stanley J, Miller MD. Biology of basal cell carcinoma (part II). J Am Acad Dermatol. 1991;24:161-75.

3. Sampaio SAP, Rivitti EA. Dermatologia. 2 ed. São Paulo: Artes Médicas; 2001. p.839-46.

4. Weedon D. Skin pathology. 2 ed. Edinburgh: Churchill Livingstone; 2002. p.765-72.

5. Christenson LJ, Borrowman TA, Vachon CM, Tollefson MM, Otley CC, Weaver AL et al. Incidence of basal cell and squamous cell carcinomas in a population younger than 40 years. JAMA. 2005;294:681-90.

6. LeSueur BW, Silvis NG, Hansen RC. Basal cell carcinoma in children: report of 3 cases. Arch Dermatol. 2000;36:370-2.

7. Boyd AS, Shyr Y, King LE Jr. Basal cell carcinoma in young women: an evaluation of the association of tanning bed use and smoking. J Am Acad Dermatol. 2002;46:706-9.
8. Kevan G, Lewis MS, Martin A, Weinstock MD. Nonmelanoma skin cancer mortality (1988-2000). Arch Dermatol. 2004;40:837-42.

9. Ramachandran S, Fryer AA, Strange RC. Genetic factors determining cutaneous basal cell carcinoma phenotype. Med Pediatr Oncol. 2001;36:559-63.

10. Fletcher CDM. Diagnostic histopathology of tumors. 2 ed. New York: Churchill Livingstone; 2000. p.1375-80.

ENDEREÇO PARA CORRESPONDÊNCIA / MAILING ADDRESS:

Maria Cristina Furian Ferreira

Serviço de Anatomia Patológica, Hospital e

Maternidade Celso Pierro, $s / n$

Jardim Ipaussurama

13060904 Campinas SP

Tel.:/Fax: 1937298421

E-mail:patologia@bmcp.puc-campinas.edu.br

Como citar este artigo / How to cite this article: Almeida ACC, Yamashita T, Conte B, Mattos AC, Veríssimo RP, Ferreira MCF. Frequência do carcinoma basocelular na população menor de 50 anos: estudo do serviço e revisão de literatura. An Bras Dermatol. 2009;84(6):692-4. 